https://helda.helsinki.fi

\title{
Method and appraisal in economics, 1976-2006
}

\section{Mäki, Uskali}

2008

Mäki , U 2008 , ' Method and appraisal in economics, 1976-2006 ' , Journal of Economic Methodology , vol. 15 , no. 4 , pp. 409-423.<

http://www.tandfonline.com/doi/pdf/10.1080/13501780802507735?needAccess=true >

http://hdl.handle.net/10138/232196

publishedVersion

Downloaded from Helda, University of Helsinki institutional repository.

This is an electronic reprint of the original article.

This reprint may differ from the original in pagination and typographic detail.

Please cite the original version. 


\section{Method and appraisal in economics, 1976-2006}

\section{Uskali Mäki}

To cite this article: Uskali Mäki (2008) Method and appraisal in economics, 1976-2006, Journal of Economic Methodology, 15:4, 409-423, DOI: 10.1080/13501780802507735

To link to this article: https://doi.org/10.1080/13501780802507735

曲 Published online: 12 Dec 2008.

5 Submit your article to this journal

LII Article views: 117

Q View related articles $₫$

47 Citing articles: 2 View citing articles 준 


\title{
Method and appraisal in economics, 1976-2006 ${ }^{1}$
}

\author{
Uskali Mäki* \\ Academy of Finland, Helsinki, Finland
}

Ladies and gentlemen, Dr Spiro Latsis,

I am honoured and delighted to address you tonight on this important occasion. I consider this an important occasion not only for Dr Latsis and this University, but also for the field of the methodology and philosophy of economics. Honorary doctorates are not abundant in this field - yet (but I would expect there to be many more in the coming years).

I will begin and end this note with an autobiographical remark.

In the autumn of 1971, I was a fresh undergraduate student, eager to start studies in economics. After the first few classes of the course on introductory economics, having been exposed to models and assumptions such as those of perfect competition, my eagerness took an unexpected twist. I was puzzled enough to conclude that it was impossible for me to continue without combining my economics studies with my interest in philosophy. I decided to become a specialist in the methodology and philosophy of economics. However, at that time, such a research field, as a field, did not yet exist. It was easy to follow what was published - and because so little was published, it was relatively easy to catch up, and to read, in the course of a few years, virtually everything that had been published during the previous 200 years or so (this would be close to impossible today given the very different scale of publications in this area and the far more severe pressures on students). Naturally, I read everything new that was published, and this was not much in the beginning, thus I was probably among the first to read Spiro Latsis' 1972 paper in the British Journal for the Philosophy of Science. But the literature gradually started accumulating. There were Larry Boland's several articles beginning in the late 1960s, then his 1982 book on economic method (Boland 1982). There was Alex Rosenberg's 1976 book on microeconomic laws (Rosenberg 1976), and Hollis and Nell's peculiar 1975 book on rational economic man (Hollis and Nell 1975). There was an increasing number of journal articles and other contributions of book length, such as Hutchison (1977), Wong (1978), Stewart (1979), Katouzian (1980), then Blaug (1980), Hausman (1981), and Caldwell (1982). By this time, the world had changed, and the field of economic methodology was taking shape as an institutionalized research field.

Of all that was published in the 1970s, it was Spiro Latsis's edited volume with Cambridge University Press in 1976 that was to play a major role in setting the research agenda. Method and Appraisal in Economics became the major source of inspiration for the next several years. This volume, together with Latsis's 1972 article that I mentioned, 'Situational Determinism in Economics' in the British Journal,

*Email: uskali.maki@helsinki.fi 
served to shape the orientation of the emerging field of economic methodology. Latsis was a student of Imre Lakatos, the Hungarian-born philosopher of science at the London School of Economics, who took Karl Popper's ideas closer to the complexities of the history of science. The rise of Lakatosian economic methodology was to coincide with the rise of economic methodology as a field. We may therefore say that Spiro Latsis not only helped establish the Lakatosian project within economic methodology, but that he helped establish the field of economic methodology itself. Thanks partly to him, there was now a field to which I had devoted myself before it was there.

To conclude my first autobiographical note, I gratefully admit that even though this aspiring economic methodologist never became a full-blown Lakatosian nor shared the Lakatosian research agenda, these works played an important role in my intellectual development. As I started teaching economic methodology later in the 1970s, I often included Latsis's British Journal article in my reader for the students.

\section{Three contributions}

As I see it, Latsis's contributions have been at least threefold. He identified 'situational determinism' as the core principle of neoclassical economics and offered a normative appraisal of it. He introduced Lakatosian principles of describing and appraising economic theories and programmes. And he played a role as organizer and sponsor of activities in economic methodology.

\section{Characterization and appraisal of situational determinism}

The first contribution was his work on what he called situational determinism and its rivals in the context of the theory of the firm (and it was obvious that the significance of this theme reached beyond the boundaries of firm theory). I think 'situational determinism' is an apt label (more so than Popper's 'situational analysis') for the image of things conveyed by the traditional neoclassical approach to economic modelling.

According to situational determinism, the situation in which an agent finds itself determines its behaviour. The inner workings of the agent do not matter, as the external situation completely constrains its behaviour. The agent's situation is construed so as to leave it with no choice: in a single-exit situation, there is just one way to go, so there is no room for genuine choice, decision-making, and entrepreneurship. Behaviour becomes a matter of reaction instead of action.

Latsis argued that situational determinism is a degenerating research programme: the model of monopolistic competition as a successor of perfect competition within the same programme fails to make even theoretical progress in the sense of generating novel predictions. Therefore, a case can be made against situational determinism and for an alternative research programme, economic behaviouralism. Unlike situational determinism, economic behaviouralism pays serious attention to the psychological and organizational details of the inner functioning of economic agents. On this programme, behaviour is not determined by the situation alone, but the inner environment of agents becomes relevant, and behaviour becomes a matter of genuine decision-making in multiple-exit situations. While the programme of situational determinism is autonomous with respect to 
psychology and organization theory, economic behaviouralism is dependent on contributions from these fields of inquiry.

Much has happened since the early 1970s in this area. For one thing, monopolistic competition has made a comeback and, when conjoined with increasing returns, has turned out to be a fertile source of explanatory force in bringing together fields such as international trade, urban and regional economics, growth theory and development economics. A more generous appraisal might therefore be justified today (yet, this may be complicated by 'monopolistic competition' not having been stable in its meaning through these developments). On the other hand, when presenting and defending 'economic behaviouralism' as a major rival to situational determinism, Latsis's vision was just right. We now have 'behavioural economics' as a growing and fruitful stream of economic inquiry that has an identity and label of its own. It combines experimental and psychological (and recently neuroscientific) work with some traditional themes in economics, and is indeed interested in the inner workings of economic agents. In the sphere of the theory of the firm, we now have a plethora of new theories of the firm that provide accounts of different aspects of firm organization and behaviour, including principal-agency theories, transaction cost theories, property rights theories, resource and capability theories, and so on. Much recent work on firm behaviour is based on crossing traditional disciplinary boundaries, for example by merging perspectives from economics with those from law or strategic management. And among other things, entrepreneurial activity has attracted much more attention than was the case in the early 1970s.

Economic inquiry has moved towards directions that Latsis envisaged and recommended, but it did so independently of his particular Lakatosian arguments. Yet I would think that there are still unexploited intellectual opportunities contained in his way of portraying the alternative images and strategies in terms of (situational) single-exit and (procedural) multiple-exit modelling. There are some fruits to be collected by intelligent follow-up research framed in these terms, so I would list this as one of the challenges for future work.

\section{Lakatosian economic methodology introduced and applied}

The developments of Lakatosian economic methodology, on the other hand, did not proceed independently of Latsis's contributions. Herein lies his second contribution. Using the theory of the firm as a case study, he was the first to illustrate the functioning of the Lakatosian framework by arguing that situational determinism is a scientific research programme and that it is a degenerating programme. The argument required framing the issues in Lakatosian terms, those of hard core, protective belt, negative and positive heuristics, and theoretical and empirical progress. They provide a methodology of normative appraisal - not prescription that should meet some descriptive adequacy requirements. It is this framework that was to dominate large parts of economic methodology for the next decade and a half or so.

Just to briefly remind the audience of the basics of Lakatos's (1970) methodology of scientific research programmes (MSRP), a research programme is a sequence of theories governed by a set of rules or heuristics. Each theory consists of two kinds of statements, those constituting the hard core, and those characterizing its protective 
belt. All theories in the sequence share a common hard core, while each has a more or less different protective belt. The heuristic of the programme consists of a set of rules that govern the movements along the sequence. The negative heuristic is the simple proscription against revising or rejecting the hard core, while the positive heuristic instructs how to modify the protective belt so as to settle tensions between theory and empirical evidence while at the same time protecting the hard core. Hence what we get is a sequence of theories sharing a hard core and governed by positive heuristic for what they do not share, namely the protective belt. In Latsis's application, the models of perfect competition and monopolistic competition belong to the same research programme of situational determinism. They are members in the sequence of theories that share hard core assumptions such as profit maximization, perfect information, and independent decisions by firms. They differ little with regard to their protective belt statements: one assumes homogeneous products, while the other assumes product differentiation. The positive heuristic of the programme consists of the rules guiding the analysis of equilibrium conditions and comparative statics.

On the MSRP, theories are held to be empirically accountable, but empirical evidence is channelled to hit the protective belts only, while leaving the hard core intact. Theory modification is constrained by empirical evidence, but it is also constrained and guided by the tenets of a programme so as to guarantee continuity across theory changes. This is hoped to rule out ad hoc modifications. Yet theory modification is a key idea in the MSRP. Empirical accountability is not a matter of instant fit between theory and the data; it is rather a matter of dynamic empirical performance across the sequence of theories. This is where the concept of progress comes in.

The normative appraisal of a programme is in terms of progress. A progressive programme is one that exhibits both theoretical progress (it yields a novel prediction each time there is a move to another theory along the sequence) and empirical progress (those predictions fail to be contradicted by evidence). A degenerating programme is one that fails to exhibit theoretical and empirical progress. In Latsis's application, situational determinism comes out as a degenerating programme, since monopolistic competition fails to yield novel predictions in the absence of required input data.

Normative appraisal is essentially comparative. It is comparative in that theory versions are to be compared across the sequence within a programme. And it is comparative in that a programme being appraised is to be compared to other programmes for its relative progressiveness. In principle, degenerating programmes should be refuted and replaced by progressive programmes. It is well known that Lakatos was unable to solve the difficult problem of setting rules for determining the conditions under which such refutation and replacement should happen. For how long (and, I would add, through how serious failures) is a research programme permitted to degenerate before being overthrown? The heuristic of a programme would not tell as it is only supposed to govern what happens within the programme. In line with this inconclusiveness in Lakatos's framework, Latsis did not rush to radical conclusions in his application. He granted that the programme of situational determinism may successfully serve as a test bed for the development mathematical techniques, and that it can be used for answering certain questions that behaviouralism cannot answer. He was thus unwilling to pass final judgement in 
appraising these rival programmes. This was surely understandable also due to the young age of the behavioural programme.

In the course of the subsequent several years, others published numerous applications of the Lakatosian framework, including those to international trade, general equilibrium, new classical macro, and to schools of economic thought such as Keynesian, Marxian, Austrian, and neo-Ricardian. Few of these studies did what the framework recommended doing, namely comparing rival research programmes for their relative progressiveness. They typically examined one programme at a time. It is also noteworthy that even though Latsis did compare two programmes, he did not compare their rates of progress - only situational determinism was gauged in terms of progress.

\section{Two conferences}

There is a sense in which the heyday (or even dominance in the field) of Lakatosian economic methodology lasted for 15 years. And there is a sense in which Spiro Latsis's contribution was crucial for both the beginning and the ending of this period. This was in his role as a sponsor and as an organizer. Method and Appraisal in Economics was published in 1976 and was based on a conference that took place in the Greek town Nafplion in 1974 (participants have praised this as the conference of their life time). Latsis was the organizer of this event that launched the Lakatosian period in economic methodology. Fifteen years later, in 1989, there was another fabulous conference on the Italian island of Capri, now sponsored by Latsis who had left the academia. This event became a collective act of burial of Lakatos in economic methodology, as it were. I was too young to witness the Nafplion meeting, but I was at Capri, and indeed the atmosphere was that of a happy funeral. The book based on the conference, Appraising Economic Theories, edited by Mark Blaug and Neil DeMarchi, appeared in 1991, 15 years after the publication of Method and Appraisal. But those were important 15 years since they also were the formative years of contemporary economic methodology as an institutionalized collective endeavour.

\section{Criticisms of Lakatosian economic methodology}

One should not exaggerate: not all work in economic methodology during that period shared the Lakatosian agenda (such as that of Alex Rosenberg, Dan Hausman, and myself), and there were criticisms of it from the beginning (indeed, already in Method and Appraisal by contributors such as John Hicks and Axel Leijonhufvud, and later by Wade Hands and others). Economic methodology has now more broadly moved beyond the Lakatosian agenda by addressing new questions about economics and answering them in novel ways (see DeMarchi 1993; Backhouse 1994a, 1994b, 2008; Davis, Hands, and Mäki 1998; Backhouse, Hausman, Mäki, and Salanti 1998; Hands 2001; Kincaid and Ross 2009; Mäki 2009).

Even though the Lakatosian period in economic methodology is over, it is still important and instructive to be clear about the flaws of the framework. In the remainder of this talk, I will construe the subsequent developments in economic methodology as a process of seeking to remove those flaws. This helps see how we got here from there, as the field's agenda evolved between 1976 and 2006. 
From its early stages, there has been a close alliance between economic methodology and the history of economic thought. The Lakatosian framework was fit for this alliance given its focus on the dynamics of progress and its explicit appeal to the verdict of historical evidence in meta-methodological considerations. Indeed, it is part of the overall Lakatosian doctrine that methodology should be sensitive or accountable to evidence pertaining to the history of science. This prepared the way for many contributors to use historical evidence against the methodological theory. Some other criticisms derived from philosophical and other conceptions of science (see Rosenberg 1986; Hands 1985, 1991; Hausman 1992; Mäki 1990; Backhouse 2009).

Without trying to be exhaustive, we may list the following criticisms against the MSRP:

(1) There is no easily identifiable stable hard core and positive heuristics in economic theorizing.

(2) There is no active generation of novel predictions in economics.

(3) There is no room in the MSRP for straightforward inductive support by empirical evidence.

(4) There is no systematic role in the MSRP for social institutions and their history (they were expelled to the footnotes as Lakatos has it).

(5) There is no systematic account in the MSRP of how progress in terms of novel predictions connects with the goal of approaching truths about the real world.

Challenges (1) and (2) complain that economics lacks features that would be required for the MSRP to apply. Challenges (3), (4) and (5) complain that economics has certain important features that the MSRP misses. Of these challenges, I find the last three (3)-(5) as more obviously serious. I will discuss the last two (4)-(5) more extensively after some brief comments on the first three (1)-(3).

(1) The first complaint, put forth by many, is about the lack in economic theorizing of an identifiable hard core that would be sufficiently stable across theory developments. Now without further qualifications, there is a possibility of overstressing this matter, and some of the criticisms may have done just that. The reason for taking this trouble seriously should not be the fact that the Lakatosian framework simplifies and idealizes. Any philosophical account - just as any theoretical account in economics and any other discipline - provides a simplified and idealized image of its subject matter. This would be reason for a serious charge only if the particular simplifications of an account were somehow responsible for missing some of the essential features of scientific practice. But thinking of the notion of a hard core, I find it obvious that in any scientific endeavour, there are more stable and less stable elements, thus it is not obviously dubious to take this idea close to an idealized extreme in the way Lakatos at times did (and at other times didn't). Indeed, Lakatos's procedure is similar to Marshall's time period analysis in this respect: fix the hard core for the short period. On the other hand, in some fields, and in virtually any field over a long enough time span, instability wins, and the idealization is defeated. Thus the adequacy of the idealizations becomes an empirical matter that cannot be decided a priori, but must be considered case by case. 
(2) There has been a lot of discussion and debate over the issue of whether economic theories do, or are able to, generate 'novel facts' at all - if they don't, Lakatos's framework will be unfit. This issue is not easy to settle given that there are many notions of novelty and that Lakatos himself held several of them (Hands 1991). It does seem obvious that a move ahead along a sequence of economic models does not characteristically help predict some entirely unheard-of facts, and also that the facts to be explained or predicted often play a role in motivating the construction of those new models - thus there is no novelty in these senses. But other kinds of novelty may be attained, such as a skilfully invented novel way of deriving familiar phenomena from the premises of standard theory. What would be novel is not some predicted phenomenon $\mathrm{P}$, but rather the derivability of $\mathrm{P}$ from theory $\mathrm{T}$. This is generally viewed as an important achievement in economics, and it surely qualifies as scientific progress of some sort. But it is less evident how weighty a role it should play in theory appraisal. More work is needed on this issue.

(3) The Popperian-Lakatosian denial of the rationality of positive evidence providing inductive support to scientific theories is a peculiarity that many commentators have found unacceptable. Everyone grants that inductive inference is not deductively valid, but this does not have to be taken to imply that it is never rational. Induction, in many guises and in many locations of the endeavour of science, seems to be among the essential features of successful scientific practice, thus dismissing it seems descriptively and normatively inadequate. More work is needed to identify and assess actually practised inductive inference in economic inquiry.

In the remainder of this talk, I'll pay my main attention to the last two complaints:

(4) The secondary or tertiary and unsystematic role (footnote role at most) given to social history and institutional structure in appraising a theory or programme is unsatisfactory in contemporary lights. The social aspects of science do not belong to footnotes only.

(5) Realists - such as the followers of Popper and Lakatos - should wish to show a systematic connection between dynamic empirical adequacy and increasing truthlikeness. They should show how the connection flows from truth to empirical adequacy rather than the other way around. This is missing in Lakatos's account.

\section{Lakatosian MSRP as a stage in the progress of economic methodology}

The remarks to follow discuss issues (4) and (5) and suggest construing Lakatos's account as a progressive stage in the development of the philosophy of science and of economics in particular. These observations deal with issues of appraisal under the headings of 'Unit of appraisal', 'Method of appraisal', 'Target of appraisal', 'Approach to appraisal'.

\section{Unit of appraisal}

The line of progress in our methodological understanding of the appropriate unit of appraisal can be simplified as follows: 
Single hypothesis $\rightarrow$ Research programme $\rightarrow$ Institutional structure

Here the idea is that Lakatos expanded the unit of appraisal from a single hypothesis to a larger research programme, and that this was an improvement in our understanding of science, economics included. However, he did not go far enough by including a systematic account of how to normatively appraise the social (academic and otherwise) institutions that shape the developments of theories and programmes. Before him, Thomas Kuhn had combined ideas akin to programme and institution in his notion of a paradigm - but Kuhn lacked an idea of rational appraisal when dealing with paradigms as such cognitive-institutional conglomerates. Here Lakatos and Kuhn had better be reconciled: everything in and about science, from the cognitive to the social, should be made subject to rational and critical appraisal.

There is another reconciliation that seems obvious when considering the unit of appraisal issue. Instead of choosing one kind of unit in exclusion of others as a general principle, the choice should be contextual: depending on the situation and the task at hand, the appropriate unit may be this and it may be that - single hypothesis, model, theory, larger programme, or institutional structure. All sorts of units have to be assessed, and their assessments do not substitute for one another. In appraising a single hypothesis, it is not sufficient to check whether the institutional structure is appropriate or whether the research programme is progressive - just as in appraising the credentials of a programme or an institutional structure, testing a single hypothesis is not enough. There is no single and fixed all-purpose unit of appraisal in science.

\section{Method of appraisal}

In regard to the method of appraisal, the line of progress proceeds as follows:

Instant test of an isolated hypothesis $\rightarrow$ Appraisal of the comparative dynamics of research programmes $\rightarrow$ Appraisal of epistemically relevant characteristics of the institutional structures enabling and constraining inquiry

Again, I take Lakatos to have helped make progress in our understanding of the appropriate method of appraisal. Instead of checking isolated hypotheses against empirical evidence at an instant of time, science should estimate the comparative performance of research programmes over time in terms of the theoretical and empirical progress they are hoped to exhibit. And again we must go beyond Lakatos, since there is further meta-methodological progress to be made by insisting that the institutions of inquiry be tested and evaluated as well. Institutional appraisal is a matter of epistemic evaluation of the relevant rules and norms, conventions and customs, incentive structures and reward systems, the rhetoric and ethics of communication - the industrial organization, constitutional structure and geopolitics of economic inquiry, including its institutions for education, research, publishing, public relations, and connections with policy advice. These are epistemic institutions that require epistemic evaluation for their epistemic consequences. Here is a way of putting the reason why institutions must be appraised: research programmes are created and appraised by people acting and interacting under various institutional constraints; the existence and contents of these programmes and the reliability of these appraisals may thus crucially depend on those institutions; therefore, those institutions must themselves be appraised for their qualities 
in enhancing the innovative production and reliable appraisal of theories and programmes.

Among other things, this might help towards remedying an awkward implication of Lakatos's MSRP: namely, any research programme receiving too little attention because it is examined by nobody, or too few, or too incompetent, or too low-status scientists - will automatically be judged as degenerating. Attention, competence, prestige, and numbers are institutionally dependent matters, and they, too, must be normatively appraised. The appraisal of these matters cannot be derived from the results of Lakatosian appraisal, because the reliability of the latter is dependent on just such institutional conditions being right.

All this is to advocate the normative branch of social epistemology as we know it today. In contrast to the sociology of scientific knowledge that has a descriptive and explanatory orientation, the agenda of social epistemology also includes the task of normative appraisal (cf. Mäki 1992, 2005; Hands 1994). Social epistemology as a normative inquiry into the social conditions of knowledge acquisition has become a major approach to these issues in the last two decades or so - that is, after the 1970s contributions by Lakatos and Latsis. It is noteworthy that this advocacy does not mean a return to Kuhn's thought that was so strongly resisted by Popper and Lakatos: in Kuhn's account, the institutional structure involved in a paradigm is not normatively appraised, it is rather taken as an unquestioned given. In a sense, then, the social epistemology endorsed here is non-Kuhnian and retains a Lakatosian spirit of normative appraisal. On the other hand, it is non-Lakatosian in lifting the social aspects of inquiry from the footnotes to the core text itself.

\section{Target of appraisal}

For what qualities are the units of appraisal appraised? Any given hypothesis, research programme, and institutional structure has a vast number of properties, but only some of them are relevant to epistemic appraisal. As I see it (and here my personal philosophical convictions start playing a growing role), the line of progress goes as follows:

Static empirical adequacy $\rightarrow$ Dynamic empirical adequacy $\rightarrow$ Truthfulness / truth conduciveness

Theories, research programmes and so on are being appraised, assessed, evaluated but precisely for what, for which of their properties? It is not enough to say that they are to be appraised for their 'epistemic value' as this is not a very specific property as such. One has to add some idea about what epistemic value consists in. It is here that one's philosophical outlook starts making a difference. In the empiricist tradition, epistemic value is a matter of empirical fit, consistency with empirical evidence, or generally empirical adequacy. Static empirical adequacy can be measured in terms of an instant empirical test, mentioned above when discussing the method of appraisal. Progress in the Lakatosian sense is a dynamic form of empirical adequacy, measured in terms of the empirical performance of a programme over time. It is a matter of a research programme generating corroborated 'excess content' across the relevant sequence of theories - where content is understood in terms of the predictive implications of a theory.

But we may want to go further than this, and ask: what does dynamic empirical adequacy measure, what further quality does it manifest? Lakatos himself added 
presumptions to the effect that progress in dynamic empirical adequacy is accompanied by progress in getting closer to the truth, but this connection remained unanalyzed. It also seems obvious that for him, just as for Popper in the latter's failed doctrine of verisimilitude, the acquisition of truth was a matter of getting closer to a detailed, accurate, and complete description of concrete phenomena. But this idea can be questioned. Besides complete and detailed truth, there may be incomplete truths, that is, truths about some limited yet significant aspects of the world - such as distinct causal mechanisms. The Lakatosian framework seems unfit for dealing with such truths (Mäki 1991). In order to have an account of the possibility of making progress in economics by way of increasing truthfulness or truth conduciveness, one needs a refined account of the structure of economic theorizing and modelling - more refined than one finds in Lakatos. Such an account must be careful with the various functions served by the idealizing assumptions in models as well as with the intended truth bearers when using those models to acquire information about the world. In such an account, empirical adequacy plays a criterial role rather than being the ultimate target of appraisal. These issues are on the agenda of contemporary economic methodology. (Mäki 2004).

In this connection, it may be useful to compare the above ideas to the project on the rhetoric of economics - another development that has challenged the Lakatosian methodology of economics (e.g. Klamer, McCloskey, and Solow 1988) Let us first note Lakatos's (and Popper's) anti-psychologism: the epistemic value of a theory or research programme is an entirely objective matter and does not depend on mental matters such as whether any particular individual or group - or anybody at all believes it, is committed to it, or even understands it. Now compare this to the much debated conception of economics as rhetoric, the idea that the communication amongst economists and others amounts to persuasion of audiences. On this view, persuasiveness is the key property of theories and research programmes that is to be pursued by economists. Economists seek to persuade their audiences by various means in an ongoing conversation, and scientific success is a matter of succeeding in the attempt to persuade. Now, being persuaded and persuasiveness are notions that are best understood in terms of belief: persuasion is modification or manipulation of belief. Thus these notions are among the non-objective mental matters that are abhorred by Lakatosian anti-psychologism.

In my view, persuasiveness alone cannot constitute a sensible ultimate target, and cannot itself constitute epistemic value. But there is the further possibility that, on some stringent conditions, it plays a criterial role in assessing the epistemic value of a theory or research programme (Mäki 1995). We know that falsehoods are often very persuasive, marketed as they are by skilful persuaders such as politicians, commercial advertisers, sometimes scientists. Therefore, indeed, in order for persuasiveness to serve a criterial purpose in epistemic appraisal, we must require that certain stringent conditions be met. Again, these conditions are largely a matter of the institutional structure of the relevant epistemic communities, including the ethics of communication. Hence, even though truthtfulness were regarded as the final target of epistemic appraisal, indicators and criteria - such as empirical adequacy and persuasiveness - are needed for measuring how well the target has been captured or approached. And the reliability of those criteria depends on the adequacy of the institutional conditions for the pursuit of epistemic goals. Therefore, 
those institutional conditions themselves become included in the relevant set of criteria.

\section{Approach to appraisal}

The issue here is about how precisely we should view the relationship between truth and other qualities of economic theories in one's conception of progress.

Progress as increasing empirical adequacy, with a wish of thereby getting closer to the truth $\rightarrow$ Progress as tracking truths about the real world, with (progress in) other qualities of theories as indicators and facilitators of this achievement

This is related to the previous issue of targets: what is the direction of dependency between empirical adequacy (and other qualities, such as persuasiveness or plausibility) and truth, and how are we to approach the examination of their relationship? On Lakatos's account, we begin with evidential demands on research programmes, then we postulate - but only postulate - that meeting those demands will have a chance to take us closer to the truth, too. The alternative view is more strongly realist in outlook, suggesting that we begin with demands on truth. What it is for a model to be true, given certain explanatory interests? What is it for inquiry to make progress in the sense of tracking truths about the world? And we may say, as one possibility among others, that for a model to be true, it must help reveal a causal mechanism inside what used to be a black box. After this, we ask: what other kinds of progress may enhance meeting these demands, or help us identify moves towards meeting them? In order to answer this latter kind of question, we need ideas about further kinds of progress that facilitate truth tracking and those that serve as indicators of the extent to which truth tracking is successful.

The facilitators of truth tracking include things such as questions, techniques, and institutions. Progress in questions may be a matter of raising new kinds of questions or raising sharper versions of old questions, and this may help give answers that track new kinds of truths or sharper truths. Progress in techniques may do many things, such as help render tractable important problems and questions that otherwise may have been difficult or impossible to answer; it may also be a matter of making available new and more reliable bodies of evidence. Progress in institutions enables and encourages innovation and critical conversation, and these help track new truths and eliminate harmful falsehoods and other mistakes.

On the other hand, among kinds of progress in the indicators or criteria of truth tracking we typically include empirical advancement. This may be taken to be a matter of many kinds of thing, such as deriving novel predictions, increasingly accurate predictions, or more broadly applicable predictions, from one's theory. In considering whether to accept increases in the degree of consensus or persuasion in the relevant research community among the criteria or indicators, we must, to repeat, make their reliability dependent on the extent to which the institutions of inquiry are right.

The above suggestions imply that our methodological theories of the appropriate criteria of appraisal are themselves subject to change and progress. Lakatos permits progress in the theories about appraisal criteria, but he believed himself to have articulated the correct theory of those criteria (captured by his notions of theoretical and empirical progress, to be applied to developments within a programme). Lakatos also permits progress in the application of his favourite criteria in scientific 
practice (for example, he might have conceived of these applications becoming increasingly consistent and reliable). All this is fine as far as it goes, but I have argued above that this image of things is too narrow, therefore we need a broader array of kinds of progress that are linked to one another in a variety of ways (as facilitators and indicators). By broadening the array of effective kinds of scientific progress we ourselves make methodological progress.

We might also consider taking a step further. On Lakatos's view, the correct criteria of appraisal are supposed to be universal and fixed across our theories and applications of them. In contrast, we may need an idea of progress in the criteria of appraisal themselves. As science changes and is done in changing institutional conditions, we should be prepared for the possibility that the appropriate criteria of appraisal also change. This creates another possibility for making methodological progress.

I should separately warn against being too narrow in the other direction. This inadvisable trend could be characterized as becoming over-impressed by the institutional shaping of scientific practice and giving up the very idea of normative appraisal. While Lakatos downplayed the importance of institutional realities, the reverse trend has now become popular in the metatheoretical study of economics, shifting attention away from rules of appraisal of the sort we find in Popper and Lakatos. But we should not forget that much of scientific practice deals with how theories are linked to empirical evidence, therefore economic methodologists also need to reintroduce the Lakatosian focus on this level. My proposal is to pursue methodological progress by combining descriptive, explanatory, and normative perspectives to economics while acknowledging the multiplicity and complexity and interconnectedness of the various kinds of conditions and criteria, from cognitive to institutional, that shape - and should shape - economic inquiry. Put in terms of appraisal, a simplified version of my proposal goes: appraise theories and explanations for their truth by appraising their empirical performance and by appraising the institutional conditions of theoretical and empirical inquiry. As I see it, Lakatos's MSRP seriously deals with issues of empirical performance only, whereas our horizons should be expanded so as to encompass issues of truth and institutions as well (while Lakatos considered the former by postulation and relegated the latter to footnotes).

One way of formulating some of these ideas is to suggest that the 'naturalization' of economic methodology is to be taken a few steps further. Lakatos's methodology is naturalistic in the sense of being made accountable to empirical evidence pertaining to the actual history of science. The next step, already being taken by many, is to make the contents of the standards used in methodological description, appraisal, and prescription dependent on the contents of the best scientific theories about the structure and functioning of the cognitive agents and relevant epistemic institutions (cf. Hausman 2001; Hands 2001; Mäki 1992, 2005; Zamora 2009). The contents of methodology, in other words, should interact with the contents of fields such as cognitive science, sociology of science, and the economics of organizations and institutions.

Let me support this idea with an analogy to an argument presented some three decades ago. The argument was presented by Spiro Latsis in 1972 and again in 1976, and I have already summarized it above. Latsis argued that economic theory based on the programme of situational determinism was to be improved by making it less 
autonomous and closed with respect to research fields dealing with the structure and functioning of economic agents - such as psychology and organization theory. In analogy to Latsis' argument, economic methodology is to be improved by making it less autonomous, by welcoming influences from similar substantive research fields so as to enrich our image of real scientific agents in action. What we need is a behavioural and institutional economic methodology to highlight the complex mental and social processes that shape the development of economic inquiry.

[After I had delivered this address, Chris Mantzavinos gave me a copy of a brief paper by Spiro Latsis, published in 1996 in a Festschrift for Axel Leijonhufvud. Entitled 'Nafplion Revisited', the paper surprised and delighted me by suggesting the same analogy between situational determinism and 'rationalist' accounts of science, and by emphasizing the need to go beyond them by examining the causally influential ways in which internal mental factors and external social factors shape inquiry especially in the social sciences. Even though busy with other business - or perhaps thanks to it? - Dr Latsis keeps making sharp and up-to-date observations about Life Among the Econ, to borrow Leijonhufvud's expression.]

\section{Conclusion}

The Lakatosian stage in the progress of the philosophy and methodology of economics has served a useful role in helping launch a systematic and collective field of inquiry. In the course of the 30 years between 1976 and 2006, the field has advanced beyond that stage, but much of the spirit of the original ambitions had better be retained. As much as ever, if not more than ever, we need economic methodologies for normatively appraising assumptions, models, theories, explanations, research programmes, and, importantly, for appraising academic and other institutions for their capacities in helping us acquire truths about the real world. Given the increasing complexity, diversity, and fragmentation of economics itself, practising economists should be increasingly receptive to methodological reflection.

I would like to congratulate Universität Witten/Herdecke for making the wise decision of awarding Spiro Latsis an honorary doctorate. I began this talk with an autobiographical note, and promised to finish it with another. About 10 years ago, soon after my arrival at Erasmus University of Rotterdam, I made a formal proposal to nominate Spiro Latsis for an honorary doctorate at Erasmus University. The proposal was not accepted by those who had the power to decide. So Dr Latsis had to wait for another decade - and another place - to receive the well-deserved title. Congratulations.

\section{Note}

1. Talk given on the occasion of awarding Dr Spiro Latsis an Honorary Doctorate at Witten/ Herdecke University, 9 November 2006.

\section{References}

Backhouse, R. (Ed.) (1994a), New Directions in Economic Methodology, London: Routledge. Backhouse, R. (1994b), "The Lakatosian Legacy in Economic Methodology," in New Directions in Economic Methodology, ed. R. Backhouse, London: Routledge, pp. 173-191. 
Backhouse, R. (2009), "The Rise and Fall of Popper and Lakatos in Economics," in Handbook of the Philosophy of Economics, ed. U. Mäki, Amsterdam: Elsevier.

Backhouse, R., Hausman, D., Mäki, U., and Salanti, A. (Eds.) (1998), Economics and Methodology: Crossing Boundaries, London: Macmillan.

Blaug, M. (1980), The Methodology of Economics, Cambridge: Cambridge University Press.

Blaug, M., and DeMarchi, N. (Eds.) (1991), Appraising Economic Theories: Studies in the Methodology of Research Programs, Aldershot: Edward Elgar.

Boland, L. (1982), Foundations of Economic Method, London: Allen \& Unwin.

Caldwell, B. (1982), Beyond Positivism: Economic Methodology in the Twentieth Century, London: Allen \& Unwin.

Davis, J., Hands, W.D., and Mäki, U. (Eds.) (1998), The Handbook of Economic Methodology, Cheltenham: Edward Elgar.

DeMarchi, N. (Ed.) (1993), Post-Popperian Methodology of Economics, Dordrecht: Kluwer Publishers.

Hands, D.W. (1985), "Second Thoughts on Lakatos," History of Political Economy, 17, $1-16$.

Hands, D.W. (1991), “The Problem of Excess Content: Economics, Novelty, and a Long Popperian Tale," in Appraising Economic Theories, eds. M. Blaug and N. DeMarchi, Aldershot: Edward Elgar, pp. 58-75.

Hands, D.W. (1994), "The Sociology of Scientific Knowledge," in New Directions in Economic Methodology, ed. R. Backhouse, London: Routledge, pp. 75-106.

Hands, D.W. (2001), Reflection Without Rules: Economic Methodology and Contemporary Science Theory, Cambridge: Cambridge University Press.

Hausman, D.M. (1981), Capital, Profits, and Prices: An Essay in the Philosophy of Economics, New York: Columbia University Press.

Hausman, D.M. (1992), The Inexact and Separate Science of Economics, Cambridge: Cambridge University Press.

Hausman, D.M. (2001), "A New Era for Economic Methodology," Journal of Economic Methodology, 8, 65-68.

Hollis, M., and Nell, E. (1975), Rational Economic Man, Cambridge: Cambridge University Press.

Hutchison, T. (1977), Knowledge and Ignorance in Economics, Oxford: Blackwell.

Katouzian, H. (1980), Ideology and Method in Economics, London: Macmillan.

Kincaid, H., and Ross, D. (Eds.) (2009), Oxford Handbook of the Philosophy of Economics, Oxford: Oxford University Press.

Klamer, A., McCloskey, D., and Solow, R. (1988), The Consequences of Economic Rhetoric, Cambridge: Cambridge University Press.

Lakatos, I. (1970), "Falsification and the Methodology of Scientific Research Programmes," in Criticism and the Growth of Knowledge, eds. I. Lakatos and A. Musgrave, Cambridge: Cambridge University Press, pp. 91-196.

Latsis, S.J. (1972), "Situational Determinism in Economics," British Journal for the Philosophy of Science, 23, 207-245.

Latsis, S.J. (Ed.) (1976), Method and Appraisal in Economics, Cambridge: Cambridge University Press.

Latsis, S.J. (1996), "Nafplion Revisited," in Inflation, Institutions and Information: Essays in Honour of Axel Lijonhufvud, eds. D. Vaz and K. Velupillai, London: Palgrave Macmillan, pp. 24-32.

Mäki, U. (1990), "Methodology of Economics: Complaints and Guidelines," Finnish Economic Papers, 3, 77-84.

Mäki, U. (1991), "Comment on Hands," in Appraising Economic Theories, eds. N. DeMarchi and M. Blaug, Aldershot: Edward Elgar, pp. 85-90. 
Mäki, U. (1992), "Social Conditioning of Economics," in Post-Popperian Methodology of Economics, ed. N. DeMarchi, Dordrecht: Kluwer Publishers, pp. 65-104.

Mäki, U. (1995), "Diagnosing McCloskey," Journal of Economic Literature, 33, 1300-1318.

Mäki, U. (2004), "Some Truths About Truth for Economists, Their Critics and Clients," in Economic Policy-Making Under Uncertainty: The Role of Truth and Accountability in Policy Advice, eds. P. Mooslechner, H. Schuberth, and M. Schurtz, Cheltenham: Edward Elgar, pp. 9-39.

Mäki, U. (2005), "Economic Epistemology: Hopes and Horrors," Episteme. A Journal of Social Epistemology, 1, 211-220.

Mäki, U. (Ed.) (2009), Handbook of the Philosophy of Economics, Amsterdam: Elsevier.

Rosenberg, A. (1976), Microeconomic Laws, Pittsburgh: Pittsburgh University Press.

Rosenberg, A. (1986), "Lakatosian Consolations for Economists," Economics and Philosophy, 2, 127-139.

Stewart, I. (1979), Reasoning and Method in Economics: An Introduction to Economic Methodology, London: McGraw-Hill.

Wong, S. (1978), The Foundations of Paul Samuelson's Revealed Preference Theory. A Study by the Method of Rational Reconstruction, London: Routledge \& Kegan Paul.

Zamora Bonilla, J. (2009), "The Economics of Scientific Knowledge," in Handbook of the Philosophy of Economics, ed. U. Maki, Amsterdam: Elsevier. 